\title{
Nanoporous Tungsten for Improved Mechanical Performance and Safety in Nuclear Control Rod Cladding
}

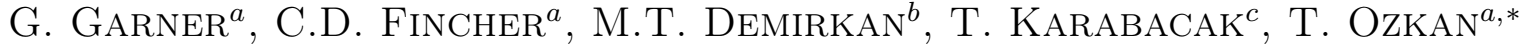 \\ AND A.A. POLYCARPOU ${ }^{a}$ \\ ${ }^{a}$ Department of Mechanical Engineering, Texas A\&M University, College Station, TX, 77843, USA \\ ${ }^{b}$ Department of Materials Science and Engineering, Gebze Technical University, Gebze, Kocaeli, 41400, Turkey \\ ${ }^{c}$ Department of Physics \& Astronomy, University of Arkansas at Little Rock, Little Rock, AR 72204, USA
}

Driven by both the implications of the recent disaster in Fukushima as well as the coming maturity of fusion reactors in energy infrastructure, the nuclear industry is experiencing a renaissance not only in reactor design and fuel systems but also in safety. However, the combination of high temperature, high pressure, and radiation intensity of a reactor core poses a challenge to material selection for engineers, particularly related to nuclear cladding. For example, in a pressurized water reactor, the most prevalent reactor type currently in operation, control rod cladding can be subjected to temperatures over $500^{\circ} \mathrm{C}$, pressures at $15 \mathrm{MPa}$, and a neutron flux of $3.5 \times 10^{19}$ neutrons per $\mathrm{cm}^{2}$ s. Thus, creep and cracking pose a threat to the cladding's functional integrity. As a result, high fracture toughness, low thermal expansion coefficient, and wear resistance become crucial metrics for the design and selection of nuclear cladding material for control rods. In response to these metrics, boron carbide $\left(\mathrm{B}_{4} \mathrm{C}\right)$ and $\mathrm{Ag}-\mathrm{In}-\mathrm{Cd}$ alloy have emerged as promising candidates for usage in control rod claddings. However, nanoporosity can impart significant mechanical advantages including higher fracture toughness, increased defect annihilation, and suppressed irradiation swelling. Density-modulated tungsten thin films with tunable nanoporosity can be manufactured through sputter coating. Consequently, density-modulated tungsten thin films have the potential to contribute to next-generation control rod cladding. Thus, the objective of this paper is to investigate the suitability of density-modulated tungsten thin films for nuclear control rod cladding through the analytical hierarchy process. Overall, conservative analytical hierarchy process analysis indicates that nanoporous tungsten is competitive with $\mathrm{B}_{4} \mathrm{C}$ for control rod cladding. As a result, our study may motivate current and future control rod cladding material development efforts focusing specifically on hybrid density-modulated tungsten thin film and $\mathrm{B}_{4} \mathrm{C}$ architectures for next-generation nuclear power plants.

DOI: 10.12693/APhysPolA.134.397

PACS/topics: density modulation, tungsten, nanoporosity, nuclear cladding, control rod

\section{Introduction}

While nuclear power provides significant benefits to the energy industry, maintaining ageing of reactors and infrastructure poses a significant engineering and economic challenge. The most common type of reactor currently in operation is the pressurized water reactor (PWR) [1]. In this process, water is pressurized at $15 \mathrm{MPa}$ in a closed loop and fed into the reactor core. The nuclear reaction inside the core heats the water up to $350^{\circ} \mathrm{C}[2]$. The water then exchanges heat with another fluid which drives a turbine, generating usable energy. During operation, modern reactors remain at full power in order to maximize electricity production and asset usage. However, in some areas with a high penetration of nuclear energy, reactor power must be reduced in order to respond to changes in electrical demand. During maintenance, refueling, or power reduction procedures, structures called control rods must be lowered into the reactor either in order to slow or halt the nuclear reaction. As a result, control rods are critical to the safety and integrity of the reactor.

*corresponding author; e-mail: tozkan@tamu.edu

\section{Methods}

An analytical hierarchy process (AHP) model was used to evaluate different material candidates and then rank them according to a composite merit index [3]. AHP was conducted using by analyzing parameters relevant to control rod performance and failure modes. Specifically, neutron energy absorption, resistance to thermal stress induced cracking, melting temperature, and density are considered as influential factors. Nanoporous tungsten thin films are considered, as well as four other commonly used control rod materials, namely boron carbide $\left(\mathrm{B}_{4} \mathrm{C}\right)$, hafnium, $\mathrm{Ag}-\mathrm{In}-\mathrm{Cd}$ alloy, and graphite.

\subsection{Neutron absorption cross-section}

As previously mentioned, the principle function of control rods in nuclear reactors is to reduce the power output of the core. To accomplish this, the control rods intercept and slow nuclear particles passing through them. The probability that a nuclear fuel rod will intercept a particle is correlated to a factor called "nuclear absorption cross-section", $\omega$. To function well, any material from which a control rod is fabricated must have both a relatively large neutron cross-section to slow and ultimately stop the nuclear reaction. In addition, the neutron crosssection must be divided by yield strength, $\sigma_{y}$, to account 
for the amount of plasticity that occurs in a designated region prior to failure [4]. This ratio should be minimized to reduce failure due to anisotropy [5].

In addition, the material must be able to retain its structural integrity even when exposed to high radiation levels. Here, the defect sink coefficient, $\Lambda$, is introduced, which manifests the amount of defect sinks in relation to the Zener anisotropy ratio, $Z$, which correlates to the inverse of the defect diffusion rate, and which is cubed to account for the three dimensions in which defects can move. When defect sinks are high, and the Zener anisotropy ratio is low, defect elimination is maximized [6]:

$$
M_{1}=\frac{\omega}{\sigma_{y}}\left(\frac{\Lambda}{Z^{3}}\right) .
$$

\subsection{Thermal stress resilience}

Within reactors, operating pressure normally stays constant to remain within a safe limit. However, temperature can vary significantly for various reasons, including unexpected shutdown, changes in electricity demand in some regions, and failure to remove heat from the reactor [7]. During such harsh conditions, it is imperative that the control rods both function properly and respond normally to operator commands. To minimize the risk of failure, thermally induced stress should be minimized under the resulting large temperature variations. Here, a combined material index is derived that correlates to the thermal stress experienced by a material.

To account for relevant phenomena, a thermal stress metric is first derived in agreement with the observation that thermal stress correlates with thermal expansion coefficient and elastic modulus. In addition, the temperature difference experienced by the material will be inversely proportional to its thermal conductivity

$$
\begin{aligned}
& \sigma_{\text {thermal }}=E \alpha \Delta T, \text { where } \Delta T \propto \frac{1}{\kappa}, \\
& \sigma_{\text {thermal }} \propto \frac{E \alpha}{\kappa}
\end{aligned}
$$

Note that a materials susceptibility to plasticity, and thus overall resistance to brittle cracking, is given by the following relationship [5]:

$$
\frac{E^{2}}{H^{3}} \text {. }
$$

Given these two facts, it is possible to deduce a composite index that reflects a material resistance to thermal-stress induced cracking by simply dividing the material resistance to cracking by the stress that may be opening a crack

$$
M_{2}=\frac{E \kappa}{H^{3} \alpha} \text {. }
$$

\subsection{Creep resistance and thermal property retention}

As mentioned previously, PWRs have a core operating temperature of $350^{\circ} \mathrm{C}$ [7]. However, the amount of creep that occurs is known to be related to homologous temperature, or the ratio of the operational temperature to the melting temperature [7]. Additionally, this ratio functions like a design safety factor in the event of a meltdown, which can raise temperatures experienced by the control rods to $1200^{\circ} \mathrm{C}$ or higher $[7,8]$. To enhance safety, it is important to maximize the temperature that the control rods can endure so that their structural integrity can be maintained as long as possible during a meltdown. The index given below reflects the ratio of the material melting temperature to the operational temperature of the reactor

$$
M_{3}=\frac{T_{\max }}{T_{o p}} .
$$

\subsection{Material density}

Finally, to minimize the risk of insertion failure, denser materials are given stronger consideration so that the force that a control rod may exert on unexpected obstacles can be maximized and risk of malfunctioning due to frictional effects can be minimized. In addition, denser materials may experience less force from the control rod ram if they can insert themselves with their own weight, reducing such failure risk $[2,4]$ :

$$
M_{4}=\rho \text {. }
$$

Consequently, the composite merit index for this application is considered to be the product of all the component merit indices

$$
M=\prod_{i=1}^{4} M_{i} .
$$

\section{Results}

Data for the selected materials was collected for thermal neutron absorption $\omega$, yield strength $\sigma_{y}$, melting point $T_{m}$, density $\rho$, thermal conductivity $\kappa$, Vickers hardness $H$, defect sink coefficient $\Lambda$, elastic modulus $E$, Zener anisotropy $Z$, and thermal expansion $\alpha$. The data is displayed in Table I.

The data was then analyzed using AHP and the results were calculated using MATLAB. The pairwise comparison index is displayed in Table II and the normalized scores are displayed in Table III.

\section{Discussion}

As seen in Table III, nanoporous tungsten has a score very near $\mathrm{B}_{4} \mathrm{C}$. Nanoporous tungsten has several additional advantages beyond those directly implied through AHP analysis. These advantages include relatively low capture cross-section for tungsten, which can result in slow depletion of the absorber relative to other black absorbers and decay into tungsten-rhenium alloy. As a result, nanoporous tungsten can have close to the same neutron capture cross-section as the original material, resulting in a relatively flat depletion worth curve with time. Although other materials considered here, such as 
graphite, hafnium, and Ag-In-Cd may have a higher neutron absorption cross-section, and as a result, suffer up to $20 \%$ higher absorber depletion effects, a grey rod designed with nanoporous tungsten can avoid such additional design margins. In addition, such a grey rod will have less risk of causing pellet-to-clad-interaction-related fuel failures in the reactor, due to lower "delta-power" in the fuel rods, and ultimately can lead to less radioactivity in the reactor coolant [22]. The high material density of tungsten can allow higher weight gray rod designs which are less likely to experience incomplete rod insertion events and the very high melting temperature of tungsten can lead to better accident survivability as well as reduced design constraints due to thermal considerations.

Material properties — compiled through [9-21]

TABLE I

\begin{tabular}{l|c|c|c|c|c|c|c|c|c|c}
\hline \hline \multicolumn{1}{c|}{ Material } & $\begin{array}{c}\omega \\
{[\mathrm{barns}]}\end{array}$ & $\begin{array}{c}\sigma_{y} \\
{[\mathrm{MPa}]}\end{array}$ & $\begin{array}{c}T_{m} \\
{\left[{ }^{\circ} \mathrm{C}\right]}\end{array}$ & $\begin{array}{c}\rho \\
{\left[\mathrm{g} / \mathrm{cm}^{3}\right]}\end{array}$ & $\begin{array}{c}\kappa \\
{[\mathrm{W} /(\mathrm{m} \mathrm{K})]}\end{array}$ & $\begin{array}{c}H \\
{[\mathrm{MPa}]}\end{array}$ & $\Lambda$ & $\begin{array}{c}E \\
{[\mathrm{GPa}]}\end{array}$ & $\begin{array}{c}\alpha \\
{[1 / \mathrm{K}]}\end{array}$ \\
\hline $\mathrm{B}{ }_{4} \mathrm{C}$ & 600 & $261-569$ & 2430 & 2.52 & 28 & $30 \times 10^{3}$ & 1 & $362-472$ & 0.80 & 6.3 \\
hafnium & 100 & 125 & 2156 & 13.3 & 22 & $1520-2060$ & 1 & 78 & 1.072 & 5.9 \\
Ag-In-Cd alloy & 1000 & 43 & 799 & 10.17 & 0.836 & 44 & 1 & 6.2 & 2.95 & 6.7 \\
graphite & 0.0035 & $4.8-76$ & 4000 & 2.26 & $70-120$ & 0.015 & 1 & 4.1 & 1.31 & 7.8 \\
porous tungsten $^{a}$ & 18 & 550 & 3400 & 19.3 & 125.2 & 19,600 & 10 & 224 & 1.01 & 4.18 \\
\hline
\end{tabular}

${ }^{a}$ (10-25\% porous tungsten) selected $20 \%$

Pairwise comparison matrix

TABLE II

\begin{tabular}{c|c|c|c|c|c|c|c|c|c|c}
\hline \hline & $\omega$ & $\lambda$ & $T_{m}$ & $\sigma$ & $E$ & $H$ & $\alpha$ & $\kappa$ & $Z$ & $\rho$ \\
\hline$\omega$ & 11 & 980 & 11 & 43 & 470 & 800 & $1.4 \times 10^{3}$ & $2.5 \times 10^{3}$ & $1.4 \times 10^{3}$ & $8.1 \times 10^{4}$ \\
$\lambda$ & 11 & 980 & 570 & 28 & 470 & 530 & $9.3 \times 10^{4}$ & $2.5 \times 10^{3}$ & $9.3 \times 10^{4}$ & $8.1 \times 10^{4}$ \\
$T_{m}$ & 11 & 20 & 11 & 22 & 470 & 400 & $7.2 \times 10^{4}$ & $2.5 \times 10^{3}$ & $7.0 \times 10^{4}$ & $8.1 \times 10^{4}$ \\
$\sigma$ & $8.8 \times 10^{3}$ & 120 & 180 & 340 & 38 & 80 & 140 & 120 & 140 & $4.0 \times 10^{3}$ \\
$E$ & 22 & 20 & 23 & $8.6 \times 10^{3}$ & 940 & 270 & $4.7 \times 10^{4}$ & $25 \times 10^{3}$ & $4.7 \times 10^{4}$ & $8.1 \times 10^{4}$ \\
$H$ & $1.3 \times 10^{4}$ & $1.7 \times 10^{4}$ & $2.7 \times 10^{4}$ & $4.0 \times 10^{6}$ & $3.3 \times 10^{4}$ & $9.3 \times 10^{5}$ & 98 & 94 & 96 & 25 \\
$\alpha$ & $5.5 \times 10^{3}$ & $7.5 \times 10^{3}$ & 110 & $1.7 \times 10^{4}$ & 140 & $6.8 \times 10^{9}$ & $7.2 \times 10^{5}$ & 200 & 220 & $5.6 \times 10^{3}$ \\
$\kappa$ & 22 & 20 & 23 & 140 & 19 & $4.9 \times 10^{7}$ & $1.8 \times 10^{5}$ & $5.0 \times 10^{3}$ & $3.1 \times 10^{4}$ & $8.1 \times 10^{4}$ \\
$Z$ & $4.4 \times 10^{5}$ & $5.9 \times 10^{5}$ & $9.1 \times 10^{5}$ & $1.4 \times 10^{6}$ & $1.1 \times 10^{4}$ & $5.4 \times 10^{1} 1$ & $1.8 \times 10^{9}$ & $8.9 \times 10^{6}$ & $5.6 \times 10^{7}$ & 73 \\
$\rho$ & 22 & 20 & 23 & 140 & 190 & $6.0 \times 10^{7}$ & $2.0 \times 10^{5}$ & $9.9 \times 10^{3}$ & $1.2 \times 10^{9}$ & $1.6 \times 10^{3}$
\end{tabular}

TABLE III

Normalized scores for investigated candidates for nuclear reactor control rods

\begin{tabular}{c|l}
\hline \hline Normalized score & Candidate material \\
\hline 0.089 & graphite \\
0.098 & hafnium \\
0.161 & $\mathrm{Ag}-\mathrm{In}-\mathrm{Cd}$ \\
0.314 & nanoporous tungsten \\
0.337 & boron carbide
\end{tabular}

\section{Conclusions}

Next-generation reactor technologies will require safe operation at higher temperatures and with extended lifetimes that are unattainable through current graphite control rods. The results suggest that $\mathrm{B}_{4} \mathrm{C}$ and nanoporous tungsten cladding designed with a hybrid architecture may provide an alternative option with significant benefits to nuclear reactors.

AHP analysis is particularly sensitive to longevity. However, this parameter is only poorly modelled. As a result, further research is needed to better quantify the effects of nanoporosity upon longevity. Additionally, nanoporosity has a pore size near $1-3 \mathrm{~nm}$. However, that the suitability of nanoporous tungsten films may change with varied pore size and volume fraction, this has not yet been investigated.

\section{References}

[1] J. Cleveland, International Atomic Energy Agency Report IAEA-TECDOC-949, 1997, p. 77.

[2] D.A. Petti, Nucl. Technol. 84, 128 (1989).

[3] M.M. Farag, Materials and Process Selection for Engineering Design, 3rd ed., CRC Press, 2013.

[4] C.R.F. Azevedo, Eng. Fail. Anal. 18, 1943 (2011).

[5] J. Li, C. Fan, J. Ding, S. Xue, Y. Chen, Q. Li, X. Zhang, Sci. Rep. 7, 39484 (2017).

[6] G. Pintaude, Tribology - Fundamentals and Advancements, InTech, 2013.

[7] D.B. Mitchell, D.J. Colburn, R.B. Sisk, W.H. Slagle, Trans. Am. Nuc. Soc. 97, 611 (2007).

[8] M. Steinbrăźck, C. Homann, A. Miassoedov, G. Schanz, L. Sepold, U. Stegmaier, J. Stuckert, Wissenschaft. Ber. FZKA 6746, A-159 (2004).

[9] M. Ooi, M. Teshigawara, T. Kai, M. Harada, F. Maekawa, M. Futukawa, E. Hashimoto, M. Segawa, M. Kureta, A. Tremsin, T. Kamiyama, Y. Kiyanagi, Phys. Proced. 43, 337 (2013). 
[10] R.M. Horn, B.D. Frew, P. Van Diemen, Comp. Nuc. Mat. 3, 485 (2012).

[11] A.F. Bower, Applied Mechanics of Solids, CRC Press, 2009, p. 69.

[12] V.F. Sears, Neutron News 3, 26 (1992).

[13] P.E. Hopkins, P.M. Norris, L.M. Phinney, S.A. Policastro, R.G. Kelly, J. Nanomater. 2008, 418050 (2008).

[14] A.M. James, M.P. Lord, Macmillan's Chemical and Physical Data Macmillan, 1992, p. 31.

[15] K.J. McClellan, F. Chu, J.M. Roper, I. Shindo, J. Mater. Sci. 36, 3403 (2001).

[16] A.I. Savvatimskiy, Carbon 43, 1115 (2005).

[17] H.O. Pierson, Handbook of Carbon, Graphite, Diamonds and Fullerenes, Elsevier, 1994.

[18] The Power Reactor Information System (PRIS) and Its Extension to Non-Electrical Applications, Decommissioning and Delayed Projects Information, International Atomic Energy Agency Report 428, 2017.
[19] E.A. Avallone, I.T. Baumeister, A. Sadegh, Marks' Standard Handbook for Mechanical Engineers, Vol. 10, McGraw-Hill, New York 2006.

[20] G.J. Wills, Nuclear Power Plant Technology, Wiley, 1967.

[21] T. Ozkan, M.T. Demirkan, K.A. Walsh, T. Karabacak, A.A. Polycarpou, J. Mater. Res. 31, 2011 (2016).

[22] K.J. Drudy, W.R. Carlson, M.E. Conner, M. Goldenfield, M.J. Hone, C.J. Long Jr., J. Parkinson, R.O. Pomirleanu, U.S. Patent No. 8,537,962,B1, U.S. Patent and Trademark Office, Washington, DC 2013. 